\title{
Die Evaluering van 'n Opleidingsprogram ten opsigte van Interpersoonlike Doeltreffendheid ${ }^{*}$
}

\section{$L$ I Jorgensen en S Rothmann}

Departement Bedryf-en Personeelsielkunde, Potchefstroomse Universiteit vir CHO

\section{ABSTRACT}

The South African Police Service (SAPS) is increasingly moving towards community policing. This movement makes great demands on the interpersonal efficiency of police officers and their trainers. It seems, however, that trainers in the SAPS seldom have sufficient knowledge and/or skills to manage interpersonal contact effectively. A two-group design was used to evaluate a training programme regarding interpersonal efficiency for instructors within the SAPS Training College. It transpired that interpersonal skills improved significantly after completion of the training programme. As far as qualitative impressions are concerned, it was found that certain organisational factors might inhibit the development of interpersonal efficiency of trainers

JEL $J 400$

\section{OPSOMMING}

Die Suid-Afrikaanse Polisiediens (SAPD) beweeg toenemend na gemeenskapspolisiëring. Laasgenoemde stel groot eise aan die interpersoonlike doeltreffendheid van polisiebeamptes en hul opleiers. Dit wil voorkom asof opleiers binne die SAPD selde oor genoegsame kennis en/of vaardighede beskik om interpersoonlike kontak effektief te hanteer. 'n Tweegroepontwerp is gebruik om 'n opleidingsprogram t.o.v. interpersoonlike doeltreffendheid by instrukteurs binne die SAPD-Opleidingskollege te evalueer. Die metodiek van dié kursus behels ' $n$ individuele groeistimuleringsgesprek, 'n groeigroep en interpersoonlike vaardigheidsopleiding. Die opleidingsprogram het daartoe bygedra dat opleiers na afloop daarvan meer geneig was om vanuit die self te reageer en hulself te aanvaar. Hul interpersoonlike vaardighede het ook beduidend verbeter na afloop van die opleidingsprogram. Wat die kwalitatiewe indrukke betref, blyk dit sekere faktore struikelblokke kan wees in die weg van die ontwikkeling van

\footnotetext{
- The Evaluation of a Training Programme with respect to Interpersonal Efficiency
} 
interpersoonlike doeltreffendheid.

Die Suid-Afrikaanse Polisiediens (SAPD) beweeg toenemend na gemeenskapspolisiëring en 'n groter openheid vir die gemeenskap. Ten spyte hiervan word klagtes van die publiek ontvang dat polisiebeamptes belangeloos, ongevoelig, vyandigheid en aggressief teenoor die gemeenskap optree (Du Preez, 1990). De Kock, Schutte en Ehlers (1995) bevind dat een van die oorsake van misdaad die verwydering tussen die gemeenskap en die polisie is. Dit lei tot swak verhoudinge tussen die gemeenskap en polisie en 'n swak vloei van inligting. De Kock en Schutte (1994) meen die polisie moet opgelei word in vakke wat hul verhouding met die gemeenskap sal fasiliteer. Vakke soos tale, kommunikasie, sosiologie en sielkunde moet aan die studente geleer word.

Volgens Kriek (1995) meen sekere lede van die SAPD meen dat hulle niks aan die gemeenskap verskuldig is nie. Hierdie houding manifesteer in negatiewe optrede teenoor die publiek. Goeie gemeenskapsverhoudinge is egter 'n voorvereiste vir gemeenskapspolisiëring. Verandering wat op hoofkantoor beplan word, sal slegs met sukses geïmplementeer word indien dit op grondvlak by elke lid van die SAPD suksesvol inslag vind. Volgens Midgley en Wood (1995) behels gemeenskapspolisiêring dat 'n kliëntgeoriënteerde benadering ten opsigte van polisiëring in die SAPD aanvaar word.

Die fokus op gemeenskapspolisiëring en groter openheid vir die gemeenskap wat hierdeur van polisiebeamptes verwag word, stel groot eise aan die interpersoonlike doeltreffendheid van die polisiebeamptes en veral aan hul opleiers. Alhoewel die meganika van kommunikasie by die kurrikulum van die opleidingsbeamptes van die SAPD ingesluit is, word min aandag geskenk aan dinamiese aspekte van interpersoonlike doeltreffendheid.

Interpersoonlike doeltreffendheid is noodsaaklik om die rolle van konsultant, aanbieder en/of fasiliteerder in opleiding te vertolk (Gibb, 1982; Jones \& Woodcock, 1985; Lidstone, 1988; Stuart, 1988). Dit wil egter voorkom asof opleiers dikwels nie oor genoegsame agtergrond en/of vaardighede beskik om die interpersoonlike kontak en intrapsigiese gebeure wat vereis word ten opsigte van die rolle van fasiliteerder en opleier effektief toe te pas nie (Harrold, Maxon \& Berry, 1988; Lefton, 1988; Leventhal, 1984).

Op grond van die persoongesentreerde teorie (Rogers, 1983) kan die afleiding gemaak word dat dit noodsaaklik is dat die opleier oor hö̈ vlakke van die kerndimensies van sensitiewe verhoudingvorming sal beskik ten einde interpersoonlik doeltreffend te funksioneer. Hierdie kemdimensies is respek, empatie, egtheid en konkreetheid (Cilliers \& Wissing, 1993; Rogers, 1983). Sen- 
sitiewe verhoudingvorming verwys na die vorming van fasiliterende interpersoonlike prosesse, of die skep van 'n verhoudingsklimaat wat opbouende prosesse tussen die opleier en die deelnemer/groeplid stimuleer (Cilliers \& Wissing, 1983). Aanwesigheid van hoë vlakke van die kerndimensies van sensitiewe verhoudingvorming by die opleier lei tot groeifasiliterende verandering by die deelnemer. ' $n$ Belangrike resultaat wat uit die navorsing van Carkhuff (1969) voortvloei, is dat 'n hoë vlak van psigologiese optimaliteit (selfontwikkeling) by die opleier groeistimulerend kan inwerk op deelnemers. ' $n$ Lae vlak van psigologiese optimaliteit kan die deelnemer laat agteruitgaan. Daarom behoort die opleiding van opleiers onder andere te berus op die fasilitering van psigologiese optimaliteit (Cilliers, 1988). Volgens Cilliers en Wissing (1993) moet die opleier oor die intrapersoonlike kenmerke van psigologiese optimaliteit beskik om interpersoonlik doeltreffend te kan funksioneer.

Verskeie interpersoonlike vaardigheidsopleidingmodelle het veral vanuit die psigodinamiese, humanisties-eksistensiële en die behavioristiese benaderings gegroei (Ivey \& Authier, 1978; Marshall \& Kurtz, 1982). Uit die evaluering van die verskillende opleidingsprogramme ten opsigte van interpersoonlike doeltreffendheid wat in die literatuur opgespoor kon word (bv. Anderson, 1982; Arbess \& Hubbell, 1973; Berry, 1993; Cilliers, 1988; Harrold et al., 1988; Jacobs, Brown \& Randolph, 1974; McWhirter, 1974; Russell \& Easton, 1979; Stokes \& Tait, 1980), blyk dit dat verskeie van hierdie kursusse nie voorsiening maak vir die opleiding van opleiers in organisasies nie, en/of dat hierdie kursusse nie op multikulturele groepe toegepas is nie.

Verskeie opleidingsprogramme om interpersoonlike doeltreffendheid, soos gekonseptualiseer op grond van die persoongesentreerde teorie (Rogers, 1983) en die menslike potensiaalontwikkelingsmodel (Carkhuff, 1987), te bevorder, is in Suid-Afrika ontwikkel. Cilliers (1988; 1995) en Cilliers en Wissing (1993) bevind dat hierdie opleidingsprogramme bydra tot die stimulering van interpersoonlike doeltreffendheid (gekonkretiseer as die intra- en interpersoonlike kenmerke van psigologiese optimaliteit) van bestuurders, personeelbeamptes en opleidingsbeamptes. Rothmann (1996) bevind dat 'n opleidingsprogram in fasilitering (wat interpersoonlike doeltreffendheid insluit) vir opleidingsbeamptes in die SAPD Opleidingskollege te Pretoria tot ' $n$ beduidende verbetering van interpersoonlike vaardighede aanleiding gee, maar dat die intrapersoonlike kenmerke van psigologiese optimaliteit nie beduidend verbeter het na afloop van die kursus nie. 


\section{Omskrywing en kenmerke van psigologiese optimaliteit}

Psigologiese optimaliteit word gedefinieer as die proses van konstante innerlike groei tot die volle uitlewing van die menslike potensialiteite, gekenmerk deur ' $n$ strewe na konstruktiewe interaksie met die omgewing, die verwerwing van ' $n$ innerlike lokus van evaluering en buigsaamheid ten opsigte van die toepassing van waardes (Cilliers \& Wissing, 1993). Dit blyk uit die humanistiese persoonlikheidsteorieë dat die psigologies optimaal-funksionerende persoon oor spesifieke intrapersoonlike kenmerke beskik (Lowenstein, 1993; Rogers, 1980). $\mathrm{Hy} /$ sy is geïntegreerd en selfgenoegsaam, leef in die hede, het vaste waardes, is sensitief vir sy/haar emosies en openbaar dit op "n spontane wyse sonder om kompulsief of impulsief te wees (Raskin \& Rogers, 1989; Schultz, 1977). Sy/haar selfbeeld word gekenmerk deur selfaanvaarding en positiewe selfagting (Raskin \& Rogers, 1989). Hy/sy aanvaar verantwoordelikheid vir wat hy doen, vir keuses wat hy/sy uitoefen en houdings wat hy/sy inneem (Frankl, 1978; Raskin \& Rogers, 1989). Hierdie kenmerke dien as voorvereiste vir interpersoonlike effektiwiteit (Cilliers, 1995; Cilliers \& Wissing, 1993).

Interpersoonlik word die psigologies optimaal-funksionerende persoon gekenmerk deur hoë vlakke van respek, empatie, egtheid en konkreetheid (Cilliers \& Wissing, 1993), Interpersoonlike doeltreffendheid is noodsaaklik ten einde psigologiese groei by ' $n$ individu en groep te bewerkstellig (Berry, 1993; Corey \& Corey, 1992). Interpersoonlike doeltreffendheid word in hierdie konteks gekonseptualiseer as kerndimensies van sensitiewe verhoudingvorming (respek, empatie, egtheid en konkreetheid) (Cilliers \& Wissing, 1993) en as spesifieke mikro-vaardighede bestaande uit aandaggewing, luister en waarneming, respondering, vraagstelling, minimale aanmoediging, parafra-sering, opheldering, samevatting, konfrontasie, interpretasie en reflektering van gevoel) en duidelike kommunikasie (Dickson \& Mullan, 1990; Gallagher, 1993; Ivey, 1988). Volgens Ivey (1988) bestaan daar 'n verband tussen hierdie interpersoonlike vaardighede en die kerndimensies van sensitiewe verhoudingvorming. Opleiding in die genoemde kerndimensies kan aan die hand van die menslike potensiaalontwikkelingsmodel van Carkhuff (1987) geskied, terwyl opleiding in spesifieke interpersoonlike vaardighede aan die hand van die mikroopleidingsmodel van Ivey (1988) kan plaasvind.

Die doelstelling van hierdie navorsing is om die effek van ' $n$ opleidingsprogram ten opsigte van interpersoonlike doeltreffendheid binne die SAPD Opleidingskollege te Hammanskraal te bepaal. 


\section{METODE}

\section{Navorsingsontwerp}

'n Tweegroepontwerp met ' $n$ voor-, nameting is gebruik. Dit is die voormetingnameting-kontrolegroepontwerp (Kerlinger, 1986).

\section{Samestelling van die interpersoonlike doeltreffendheidsprogram}

Die inhoud en metodiek van die opleidingsprogram ten opsigte van interpersoonlike doeltreffendheid behels die volgende aspekte:

Stimulering van die intrapersoonlike kenmerke van psigologiese optimaliteit deur middel van ' $n$ individuele groeistimuleringsonderhoud en ' $n$ groeigroepervaring, wat bestaan uit ' $n$ kombinasie van 'n T-groep (Wheelan, 1990) en 'n ontmoetingsgroep (Rogers, 1970). Inligting ten opsigte van die kenmerke van psigologiese optimaliteit en die stimuleringsproses daarvoor, is in die interpersoonlike doeltreffendheidsopleidingsprogram ingesluit.

Aanleer van die kerndimensies van sensitiewe verhoudingvorming (empatie, respek, egtheid en konkreetheid) soos gekonkretiseer deur 'n kombinasie van die menslike potensiaalontwikkelingsmodel van Carkhuff (1987) en die mikroopleidingsmodel van Ivey (1988) deur middel van interpersoonlike vaardigheidsopleiding (instruksie, gedragsmodellering en rolspel) en gestruktureerde oefeninge.

Wat die tydsverdeling van die kursus betref, is vier ure (30 minute per persoon) aan individuele groeistimulering bestee, 14 uur aan 'n groeigroep en 14,5 uur aan vaardigheidsopleiding.

\section{Ondersoekgroep}

Die ondersoekgroep is uit instrukteurs by die opleidingskollege van die SAPD in Hammanskraal ( $\mathrm{N}=42$ ) gekies. ' $n$ Ewekansige steekproef van 24 (12 per groep) is uit die totale populasie van instrukteurs by die opleidingskollege getrek. 'n Klein groep is gebruik as gevolg van die intensiteit van die opleidingsmetodes wat gebruik is (Rogers, 1974:14) en omdat dit prakties onmoontlik was om meer as 24 persone vir ses dae (opleiding en evaluering) uit die werksituasie te onttrek. 


\section{Die metingsbattery}

Die meting van die intrapersoonlike kenmerke van psigologiese optimaliteit by instrukteurs is met behulp van die Persoonlike Oriëntasievraelys (POI) (Knapp, 1976; Shostrom, 1976) gedoen. Die betroubaarheid van die POI wissel tussen 0,41 (Mensbeskouing) en 0,82 (Ondersteuningsratio) (Schulz, 1994). Die POI beskik oor konstrukgeldigheid en onderskei duidelik tussen selfgeaktualiseerde en nie-selfgeaktualiseerde persone (Leitschuh \& Rawlins, 1991; Schulz, 1994; Shostrom \& Knapp, 1966). Volgens Knapp (1976:187-202) kan die POI gebruik word om die effek van groeigroepe op selfaktualisering te bepaal. Veral die ondersteuningsratio, spontaneïteit, eksistensialiteit, aanvaarding van aggressie, KAPASITEIT vir intieme kontak, selfaktualiseringswaarde en selfaanvaarding is vatbaar vir verandering as gevolg van groeigroepe. Cilliers (1984) vind 'n beduidende positiewe verandering in elf van die twaalf skale van die POI na die aanbieding van ' $n$ opleidingsprogram in sensitiewe relasievorming. Cilliers (1988) bevind dat 'n selfontwikkelingsprogram die volgende kenmerke van psigologiese optimaliteit (soos gemeet deur die POI) by deelnemers verhoog: realiteitskontak, buigsaamheid in die toepassing van waardes, emosionele volwassenheid en ' $n$ interne lokus van kontrole.

Die meting van interpersoonlike vaardighede is met behulp van die Carkhuffskale (Carkhuff, 1967) gedoen. Elke proefpersoon het ' $n$ rolgesprek van tien minute met ' $n$ kliënt gevoer. Die onderhoud is op videoband opgeneem, waarna die vlakke van die kerndimensies van sensitiewe verhoudingvorming deur twee geregistreerde sielkundiges beoordeel is. Interbeoordelaar-betroubaarheid was groter as 0,95 vir al vier die skale.

\section{Statistiese verwerkings}

Data is met behulp van die SAS-pakket (SAS Institute, 1985) statisties verwerk. Gepaarde t-toetse is gebruik om die beduidendheid van verskille tussen die gemiddeldes van voor- en nameting by die eksperimentele en kontrolegroep te bepaal, en om te vas te stel of daar ' $n$ beduidende verskil tussen die veranderinge in hierdie groepe was (Christensen \& Stoup, 1991). Resultate word as beduidend beskou indien die p-waardes kleiner as 0,05 is. Die verkreë p-waardes (tweekantige toets) is omgeskakel na 'n eenkantige toets (Plug et al., 1988). 'n Bonferroni-aanpassing (Miller, 1981) is ten opsigte van hierdie p-waarde gemaak deur dit met twee te vermenigvuldig (aangesien daar twee stelle vergelykings was). Indien die finale p-waarde statisties beduidend is $(\leq 0,05)$, word die praktiese betekenisvolheid van resultate (d) bepaal. 
Die praktiese betekenisvolheid (d) ten opsigte van die vergelyking van die eksperimentele en kontrolegroep word gegee deur (Stat. Kons., 1990:10-10):

$d=\left(x_{E}-x_{K}\right) / s_{\text {MAKS }}$

waar

$\mathrm{X}_{\mathrm{E}}=$ die rekenkundige gemiddelde van die verskil tussen die metings van die eksperimentele groep,

$x_{K}=$ die rekenkundige gemiddelde van die verskil tussen die metings van die kontrolegroep, en

$s_{\text {MAKS }}=$ die maksimum-standaardafwyking tussen die eksperimentele en kontrolegroep.

Volgens Cohen (1977:20-27) geld die volgende afsnypunte ten opsigte van praktiese betekenisvolheid:

d $\geq 0,2$ klein effek

$d \geq 0,5$ mediumeffek

$d \geq 0,8$ groot effek

\section{RESULTATE}

\section{Psigologiese optimaliteit}

Die verskille tussen die voor- en nameting van die eksperimentele en kontrolegroep ten opsigte van die POI word in Tabel 1 uiteengesit:

Wat die psigologiese optimaliteit betref, blyk dit dat die opleidingsprogram daartoe bygedra het dat die eksperimentele groep se vlak van psigologiese optimaliteit (soos gemeet deur die POI) beduidend verhoog het betreffende die Ondersteuningsratio en Selfaanvaarding. Lede van die eksperimentele groep was dus na afloop van die opleidingsprogram meer geneig om op 'n onafhanklike en outonome wyse vanuit geinternaliseerde beginsels en motivering vir hulself te kan besluit. Hulle is ook meer geneig om hulself te aanvaar ten spyte van swakhede of tekortkominge 
Tabel 1: Die verskil tussen die voor- en nameting volgens die POI van die eksperimentele groep (EG) en kontrolegroep (KG)

\begin{tabular}{|l|l|l|l|l|l|l|}
\hline Item & \multicolumn{2}{l|}{$\begin{array}{l}\text { EG } \\
\text { Gem. S.a. }\end{array}$} & \multicolumn{2}{l|}{$\begin{array}{l}\text { KG } \\
\text { Gem. S.a. }\end{array}$} & p & d \\
\hline Tydratio (Tc) & 0.83 & 3.21 & 0.25 & 2.14 & 0.60 & - \\
\hline Ondersteuningsratio (I) & 3.50 & 4.29 & -1.33 & 6.18 & $0.03^{*}$ & $0.78_{*}$ \\
\hline $\begin{array}{l}\text { Selfaktualiseringswaarde } \\
\text { (Sav) }\end{array}$ & -0.58 & 2.23 & 0.33 & 2.31 & 0.33 & - \\
\hline Eksistensialiteit (Ex) & -0.08 & 2.43 & 0.25 & 3.67 & 0.79 & - \\
\hline Gevoelsrefleksie (Fr) & 1.33 & 2.15 & 0.25 & 1.86 & 0.20 & - \\
\hline Spontaneitteit (S) & 0.33 & 1.78 & 0.5 & 1.68 & 0.81 & - \\
\hline Selfagting (Sr) & 0.00 & 1.04 & 8.33 & 1.44 & 0.87 & - \\
\hline Selfaanvaarding (Sa) & 1.17 & 2.17 & -1.5 & 2.24 & $0.01 *$ & $1.19+$ \\
\hline Mensbeskouing (Nc) & 0.33 & 2.19 & 0.25 & 2.8 & 0.93 & - \\
\hline Sinergie(Sy) & -0.33 & 0.98 & 0.25 & 1.48 & 0.26 & - \\
\hline $\begin{array}{l}\text { Aanvaarding van aggressie } \\
\text { (A) }\end{array}$ & 0.58 & 1.44 & -0.33 & 1.44 & 0.13 & - \\
\hline $\begin{array}{l}\text { Kapasiteit vir intieme } \\
\text { kontak (C) }\end{array}$ & 0.92 & 2.02 & -0.25 & 2.87 & 0.26 & - \\
\hline
\end{tabular}

* Verskil is statisties beduidend: $p \leq 0.05$

\# Verskil is prakties betekenisvol: $d \geq 0.50$ (mediumeffek)

+ Verskil is prakties betekenisvol: $d \geq 0.80$ (groot effek)

Die verskille tussen die voor- en nameting van die eksperimentele en kontrolegroep ten opsigte van die Carkhuffskale word in Tabel 2 uiteengesit:

Tabel 2: Die verskil tussen die voor-en nameting ten opsigte van die Carkhuff-skale van die eksperimentele groep (EG) en kontrolegroep (KG)

\begin{tabular}{|c|c|c|c|c|c|c|}
\hline Item & $\begin{array}{r}\mathbf{E G} \\
\mathbf{R . G} .\end{array}$ & S.a. & $\begin{array}{r}\text { KG } \\
\text { R.G. }\end{array}$ & S.a. & $\mathbf{P}$ & d \\
\hline Empatie & 1.63 & 0.23 & 0.11 & 0.19 & $0.01^{*}$ & $8.94+$ \\
\hline Egtheid & 1.60 & 0.31 & 0.03 & 0.19 & $0.01^{*}$ & $8.21+$ \\
\hline Konkreetheid & 1.72 & 0.33 & 0.09 & 0.18 & $0.01^{*}$ & $10.22+$ \\
\hline Respek & 1.91 & 0.28 & 0.08 & 0.19 & $0.01^{*}$ & $10.22 t$ \\
\hline
\end{tabular}

* Verskil is statisties beduidend: $p \leq 0.05$

+ Verskil is prakties betekenisvol: $d \geq 0.80$ (groot effek) 
Die eksperimentele groep het na afloop van die opleidingsprogram ' $\mathrm{n}$ beduidende hoër telling ten opsigte van die vier Carkhuffskale behaal as met die voormeting. Wat interpersoonlike doeltreffendheid betref, is daar gevind dat die opleidingsprogram tot interpersoonlike vaardighede bygedra het. Die eksperimentele groep se empatie, egtheid, respek en konkreetheid het beduidend verbeter (in vergelyking met die kontrolegroep).

Wat empatie betref, is deelnemers in staat om akkurate begrip ten opsigte van die oppervlakgevoelens van kliënte te toon, hoewel dieperliggende gevoelens soms nog wanvertolk word. Ten opsigte van respek is deelnemers in staat om 'n positiewe agting en omgee vir die gevoelens, ervaringe en potensialiteite van kliënte te openbaar. Wat egtheid betref, gee deelnemers gepaste response wat nie vals voorkom nie. Ten opsigte van konkreetheid is die deelnemers in staat tot spesifiekheid of feitlikheid ten opsigte van uitdrukking met betrekking tot persoonlike of doelmatige tersaaklike inligting, in teenstelling met vae of oorveralgemeende uitdrukkings.

\section{BESPREKTING}

Die opleidingsprogram is suksesvol in die verandering van interpersoonlike doeltreffendheid (psigologies optimale funksionering en interpersoonlike vaardighede) direk $\mathrm{na}$ afloop daarvan. Wat psigologiese optimaliteit betref, blyk dit dat die opleidingsprogram daartoe gelei het dat eksperimentele groep se aanvaarding van selfverantwoordelikheid (interne lokus van evaluering) en selfaanvaarding beduidend verhoog het. Hierdie bevinding stem ooreen met dié van Cilliers en Wissing (1993) en Cilliers (1995:96-103).

Die feit dat die ander skale van die POI nie beduidend verhoog het nie, ondersteun die bevindings van Rothmann (1996:296). Die outokratiese kultuur waarbinne die deelnemers werk asook weerstand teen gevoelsuitdrukking kan moontlik beperkend inwerk op hul psigologiese optimaliteit en derhalwe die corsaak wees dat minder skale in vergelyking met Cilliers (1994) ' $n$ beduidende toename na afloop van die opleidingsprogram getoon het.

Tweedens is daar gevind dat die opleidingsprogram interpersoonlike vaardighede (soos gemeet deur die Carkhuffskale) verbeter het. Die eksperimentele groep se empatie, egtheid, respek en konkreetheid het beduidend verbeter. Hierdie resultate stem ooreen met dié van Cilliers (1994:96-103) en Rothmann (1996:296). 


\section{TEN SLOTTE}

Interpersoonlike doeltreffendheid behoort neerslag te vind in die kurrikulum van opleidingsbeamptes by die SAPD-Opleidingskollege aangesien daar bevind is dat die opleidingsprogram daartoe bydra dat die interpersoonlike doeltreffendheid verbeter. Opleiding in interpersoonlike doeltreffendheid van polisiebeamptes moet aangebied word om hulle toe te rus vir hul rol in die verandering na gemeenskapspolisiëring.

Navorsing rakende die langtermynstimulering van psigologiese optimaliteit as voorvereiste vir interpersoonlike doeltreffendheid binne die Suid-Afrikaanse Polisiediens-Opleidingskollege moet onderneem word.

Die navorsers se subjektiewe indrukke tydens die groeigroep, individuele onderhoude en aanbieding van die program was dat outoriteit, onderdrukking van gevoelens, wantroue in senior range en onsekerheid gereeld na vore gekom het. In aansluiting by Rothmann en Sieberhagen (1997) kan gestel word dat die organisasie se gedrag en die interpersoonlike doeltreffendheid van sy opleiers in die toekoms moontlik vanuit ' $\mathrm{n}$ psigodinamiese benadering (byvoorbeeld die Tavistock-benadering) (Cilliers \& Koortzen, 1996) nagevors en gestimuleer word.

\section{VERWYSINGS}

1. ALLPORT, G.W. (1961). Pattern and Growth in Personality. London : Holt, Rinehart \& Winston.

2. ANDERSON, W. (1982). A training module for preparing group facilitators. Joumal for Specialists in Group Work, 7 (2), 119-124.

3. ARBES, B.H. \& HUBBELL, R.N. (1973). Packaged Impact: a Structured Communication Skills Workshop. Journal of Counselling Psychology, 20(4),332-337.

4. BERRY, M. (1993). Changing Perspectives on Facilitation Skills Development. Joumal of European Industrial Training, 17 (3), 23-32.

5. CARKHUFF, R.R. (1967). Toward a Comprehensive Model of Facilitative Interpersonal Processes. Journal of Counselling Psychology, 14 (1), 67-72.

6. CARKHUFF, R.R. (1969). Critical Variables in Effective Counseling Training. Journal of Counseling Psychology, 16 (3), 238-245.

7. CARKHUFF, R.R. (1987). The Art of Helping. (5th ed.). Amherst, MA : Human Resource Development Press.

8. CHRISTENSEN, L.B. \& STOUP, C.M. (1991). Introduction to Statistics for the Social and Behavioral Sciences. Pacific Grove, CA : Brooks/Cole. 
9. CILLIERS, F.v.N. (1984). "n Ontwikkelingsprogram in Sensitiewe Relasievorming as Bestuursdimensie. Ongepubliseerde Doktorale Proefskrif, PU vir CHO, Potchefstroom.

10. CILLIERS, F.v.N. (1988, September). Fasiliteringsopleiding in die Bedryfsielkunde. Referaat gelewer by die Sesde Nasionale Kongres van die Sielkunde-Vereniging van Suid-Afrika, Bloemfontein.

11. CILLIERS, F.v.N. (1995). Fasiliteerderopleiding. Tydskrif vir Bedryfsielkunde, 21(3), 7-11.

12. CILLIERS, F.v.N. \& Koortzen, P. (1996, September). The Psychodynamics of Organisations. Paper presented at the 2nd Annual PsySSA Congress at the University of the Witwatersrand, Johannesburg.

13. CILLIERS, F.v.N. \& WISSING, M.P. (1993). Sensitiewe relasievorming as bestuursdimensie: Die Evaluering van 'n Ontwikkelingsprogram Tydskrif vir Bedryfsielkunde, 19 (1), 5-10.

14. COHEN, J. (1977). Statistical Power Analysis for the Behavioral Sciences. (Rev. ed.). Orlando, FA: Academic Press.

15. COREY, M.S. \& COREY, G. (1992). Groups: Process and Practice. Pacific Grove, CA: Brooks/Cole.

16. DAINOW, S. \& BAILEY, C. (1990). Developing Skills with People: Training for Person to Person Client Contact. Chichester : Wiley.

17. DE KOCK, C. \& SCHUTTE, C. (1994). Reintegrating an Alienated Police Force: Implications for South Africa. Information Update, 4 (2), 55-58.

18. DE KOCK, C., SCHUTTE, C. \& EHLERS, D. (1995). South African Police Service: Post-election legitimacy and societal integration. Information Update, 5(1), 25-37.

19. DICKSON, D. \& MULLAN, T. (1990). An Empirical Investigation of the Effects of a Micro-counselling Programme with Social Work Students. Counselling Psychology Quarterly, 3 (3), 267-283.

20. DU PREEZ, G.T. (1990). Polisiestereotipes in Teoretiese-Empiriese Perspektief. Acta Criminologica, 3 (2), 11-17.

21. FRANKL, V.E. (1978). Waarom Lewe Ek? Kaapstad : HAUM.

22. FROMM, E. (1963). The Sane Society. (2nd ed.). London : Routledge \& Kegan Paul.

23. GALLAGHER, M.S. (1993). Evaluation of an Integrative Approach to Training Paraprofessionals in Counselling Using the Problem-solving Inventory. Counselling Psychology Quarterly, 6(1), 27-38.

24. GIBB, P. (1982). The facilitative trainer. Training and Development Journal, $36(7), 14-19$.

25. HARROLD, G, MAXON, J. \& BERRY, M. (1988). Developing facilitator Skills in Staff Functions. Jourmal of European Industrial Training, 12 (1), 5-7. 
26. IVEY, A.E. (1988). Intentional Interviewing and Counseling: Facilitating Client Development. Pacific Grove, CA : Brooks/Cole.

27. IVEY, A.E. \& AUTHIER, J. (1978). Microcounseling. Springfield : Charles C. Thomas.

28. JACOBS, E., BROWN, D. \& RANDOLPH, A. (1974). Educating group counselors: A tentative model. Counselor Education and Supervision, 4, 307-309, Jun.

29. JONES, J.E. \& WOODCOCK, M.P. (1985). Manual of Management Development: Strategy, Design and Instruments for Programme Improvement. Aldershot : Gower.

30. KERLINGER, F.N. (1986). Foundations of Behavioral Research. (3rd ed.). New York : Holt, Rinehart \& Winston.

31. KNAPP, R.R. (1976). Handbook for the Personal Orientation Imventory. San Diego, CA :Edits.

32. KRIEK, R. (1995). Die Bevordering van Gemeenskapsverhoudinge deur die Suid-Afrikaanse Polisiediens (OVS-Streek): Enkele Aspekte van Beeldbestuur. Communicare, 14 (2), 18-36.

33. LEFTON, R.E. (1988). Communication: the Eight Barriers to Teamwork. Personnel Journal,18-21, Jan.

34. LEITSCHUH, G.A. \& RAWLINS, M.E. (1991). Personal Orientation Inventory Correlated with Physical Health. Psychological Reports, 69, 687-690.

35. LEVENTHAL, R.B. (1984). Working Hard to Make QWL Look Easy. Training and Development Journal, 38 (6), 59-60, Jun.

36. LIDSTONE, J. (1988). How to Conduct Successful Sales Training meetings. Joumal of European Industrial Training, 12 (2), 17-26.

37. LOWENSTEIN, L.F. (1993). Humanism-existentialism as a Basis of Psychotherapy. International Journal of Mental Health, 22 (3):93-102.

38. MARSHALL, E.K. \& KURTZ, P.D. (1982). Interpersonal Helping Skills. San Francisco, CA. Jossey-Bass.

39. MASLOW, A.H. (1954). Motivation and Personality. New York : Harper \& Brothers.

40. MASLOW, A.H. (1971). The Farther Reaches of Human Nature. New York : Viking.

41. MCWHIRTER, J.F. (1974). Counsellor Preparation Through Small Group Interaction. Small Group Behaviour, 5(1), 23-29.

42. MIDGLEY, R. \& WOOD, G. (1995). Familiar Strangers: Developing Community Policing Policy in Grahamstown. Acta Academica, 27 (1), 59 . 81.

43. MILLER, R.G. (1981). Simultaneous Statistical Inference. (2nd ed.). New York : Springer Verlag. 
44. PLUG, C., MEYER, W.E., LOUW. \& D.A., GOUWS, L.A. (1988). Psigologie Woordeboek (2de uitgawe). Johannesburg : Lexicon.

45. RASKIN, N.J. \& ROGERS, C.R. (1989). Person-centered Therapy. In R.J. Corsini \& D. Wedding (Eds.), Current Psychotherapies. Ithaca, NY: Peacock.

46. REDDY, W.B. (1985). The Role of the Change Agent in the Future of Group Work. Special issue: Critical Issues in Group Work Journal for Specialists in Group Work, 10 (2), 103-107, May.

47. ROGERS, C.R. (1970). Carl Rogers on Encounter Groups. New York: Harper and Row.

48. ROGERS, C.R. (1975). On Becoming a Person: A Therapist's View of psychotherapy. London : Constable.

49. ROGERS, C.R. (1983). Freedom to Learn for the 80's. Columbus, OH : Merrill.

50. ROTHMANN, S. (1996). Die Samestelling en Evaluering van 'n Groepfasiliteringskursus. Ongepubliseerde doktorale proefskrif, PU vir CHO, Potchefstroom.

51. RUSSELL, J.M. \& EASTON, J. (1979). Teaching the Design, Leadership and Evaluation of Structured Groups. Personnel and Guidance Journal, $57,426-429$.

52. SAS INSTTTUTE INC. (1985). SASR Users Guide: Statistics. (5th ed.). Cary, NC : SAS Institute Inc.

53. SCHULZ, G.M. (1994). Reliability and Validity of the Personal Orientation Questionnaire in South Africa. Unpublished MA dissertation, Pretoria, Unisa.

54. SCHULTZ, D. (1977). Growth Psychology: Models of the Healthy Personality. New York : Van Nostrand.

55. SHOSTROM, E.L. (1976). Actualizing Therapy: Foundation for a Scientific Ethic. San Diego, CA : Edits.

56. SHOSTROM, E.L. \& KNAPP, R.R. (1966). The Relationship of a Measure of Selfactualization (POI) to a Measure of Pathology (MMPI) and to Therapeutic Growth. American Journal of Psychotherapy, 20, 193-202.

57. Statistiese Konsultasiedienste. (1990). Praktiese Statistiek vir die Geesteswetenskappe. Potchefstroom : PU vir CHO.

58. STOKES, J.P. \& TAIT, R.C. (1980). Design of a Short Term Training Program in Group Facilitation Skills. Professional Psychology, 11 (2), 298394.

59. STUART, R. (1988). Increasing Adult Learning. Journal of European Industrial Training. 12 (2), 29-32.

60. WHEELAN, S.A. (1990). Facilitating Training Groups: A Guide to Leadership and Verbal Intervention Skills. New York : Praeger. 